\title{
AMENDMENTS
}

\section{Author Correction: Earth rotation measured by a chip-scale ring laser gyroscope}

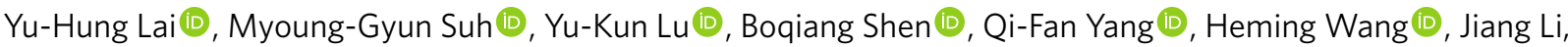
Seung Hoon Lee, Ki Youl Yang (iD and Kerry Vahala (D)

Correction to: Nature Photonics https://doi.org/10.1038/s41566-020-0588-y, published online 17 February 2020.

In the version of this Letter originally published online, in the Acknowledgements, the following sentence was missing "We also gratefully acknowledge the critical support and infrastructure provided for this work by The Kavli Nanoscience Institute at Caltech." It has now been added.

Published online: 25 March 2020

https://doi.org/10.1038/s41566-020-0622-0

(C) The Author(s), under exclusive licence to Springer Nature Limited 2020 